\title{
Japan's life sciences take integrated road
}

[токуо] Japan's main science policy-making body is expected to approve a new ten-year plan for promoting the life sciences later this month. The plan, by the Council for Science and Technology, puts particular emphasis on strengthening areas of research with possible medical applications.

The final draft of the plan, released on the Science and Technology Agency's website, calls for an approach that integrates the study of human genetics, brain science, cancer and developmental biology. It claims that these should focus not only on the molecular and cellular level, but also on the whole organism.

It also seeks more research into cancer, genetic diseases and diseases of the brain reflecting the fact that Japan faces a steep increase in the number of old people early next century.

This is the twenty-fourth in a series of reports issued by the council, which is attached to the office of the prime minister but located in the Science and Technology Agency, since its foundation in 1959. The expert group responsible for drafting the document was led by Yoshitaka Nagai, director of the Mitsubishi Kasei Institute of
Life Sciences south of Tokyo. He points out that genetic diseases provide a good example of the proposed integrated approach, as they demonstrate that the link between genotype and phenotype is not always straightforward, and that such diseases can seldom be fully understood through studies at the molecular or cellular level alone.

The report says Japan could open up a new economic frontier by developing medical, food and information industries based on life science research, as well as new electronic products such as biosensors and neurochips.

But it acknowledges many problems in Japan's present research environment - for example, Japan's comparatively low input of genome data to its databases. (The report notes that only about 10 per cent of the genome data at the DNA Database of Japan in Mishima is of Japanese origin and calls for greater output of such data by Japan.) It also highlights its lack of laboratory animals, in particular primates, for modelling human disease and testing new medical techniques.

The focus on biomedical research appears to mark a clear departure from the central role long given to molecular biology in the life sciences in Japan. According to Nagai, the report's conclusions are essential if humans are to be placed at the centre of life science research. "Reductionism has been an immensely powerful tool in biological research, but it is becoming clear that integrated approaches are needed at the moment," he says.

The report points out that the US National Institutes of Health alone spend about $¥ 1,000$ billion (US $\$ 8.8$ billion) each year on life science research. It calls for an expansion of Japan's life science budget over the next ten years, but makes no specific financial recommendations.

Indeed, in the present climate of fiscal restraint, further large expansion of the life science budget seems unlikely, given that the government has already promised a marked increase in the budget for brain science (see, for example, Nature 385, 104; 1997). But, according to Kanji Fujiki, director of the office of life science promotion at the Science and Technology Agency, the report may help to "make more efficient use of existing resources". Robert Triendl \& David Swinbanks

\section{Clinton backs Congressional efforts on genetic discrimination}

[SAN FRANCISCO] US President Bill Clinton announced on Monday that he plans to propose legislation to prevent health care companies from discriminating against consumers on the basis of genetic information. He said his bill would strengthen other legislative proposals, partly by adding sections that would not allow disclosure of genetic information unless the Secretary of Health and Human Services determined that this might support biomedical research.

Pledging his commitment to non-discrimination legislation, Clinton released an 11-page report from the Department of Health and Human Services. This concludes that current federal protective measures contain significant weaknesses concerning the denial of coverage by health plans of individuals, the setting of premiums, and the disclosure of information.

Also, although 19 states have protective measures against the misuse of genetic information by health insurers, most do not define such information sufficiently broadly to include family history, medical records and physical exams. And self-insured employers are exempt from such laws.

Unless laws specifically address the problem of misuse of genetic information, individuals will be afraid to obtain information that could be vital to their lives, the president said at a press conference. He was accompanied by Secretary of Health and Human Ser- vices Donna Shalala, who had flown in from Chicago fresh from delivering a speech on genetic discrimination to a convention held by Hadassah, a Zionist women' s organization that emphasizes education and health care, and by Vice President Al Gore.

Clinton urged Congress to move quickly on his legislation, which would build on HR 306, a bill introduced by Congresswoman Louise Slaughter (Democrat, New York) to prohibit health plans from denying, refusing to renew, cancelling or changing the terms of a health insurance policy based on genetic information. Health plans would not be able to require genetic tests or to disclose genetic information to a third party.

The President's bill is intended to extend genetic information protective measures recently enacted under the KassebaumKennedy health reform package to selfinsured employers, uninsured workers, people switching jobs, and other groups. The Kassebaum-Kennedy law prohibits insurance companies from refusing health coverage based on a person's medical history, including genetic information. HR 306 also applies tax penalties to violators and allows individuals to sue their health plan for punitive damages if they feel that they have been discriminated against.

Members of Hadassah, the largest women's organization in the United States with 300,000 members, called such legisla- tion vital. "There's been a clamouring for a commercially available test in our community, but when we started to become aware of the history of insurance discrimination on this issue, it had a chilling effect," says Amy Rutkin, director of American affairs for Hadassah. The group has recruited co-sponsors for the bill and has urged its members to discuss their concern about discrimination in their communities.

HR 306 has 135 co-sponsors among legislators and 65 endorsing organizations, but has so far failed to make the commerce committee agenda. Olympia Snowe (Republican, Maine), is co-sponsoring the bill in the Senate, which also has been slow to move on it. One reason is that biotechnology and pharmaceutical industry executives are concerned that such legislation would excessively protect health databases from research usages and distinguish genetic information from other medical data.

Some, such as Paul Billings, chief medical officer at the Heart of Texas Veterans Integrated Service Network and an expert in genetic discrimination issues, see Clinton's statement as a watershed moment in US history by declaring that genetic discrimination in health matters is unlawful.

"We are recognizing how important an environment of non-discrimination is to maximizing the benefit of this technology," says Billings.

SallyLehrman 